\title{
A Dash of Psychopathy May Help Women Entrepreneurs
}

\author{
Lou Marino (University of Alabama) \\ Reg Tucker (East Carolina University)
}

\section{KEYWORDS: Entrepreneurship, Management, Women.}

The term "psychopath" conjures up dark images of serial murderers, straitjackets, stalkers and that maniac in the corner office. It is part of the Dark Triad (narcissism, Machiavellianism and psychopathy) and always viewed as negative and harmful -- but are there actually conditions, professions and environments in which non-clinical levels are actually beneficial? Can a modest amount of psychopathy allow you to get things done or overcome biases and obstacles? Entrepreneurship is perhaps one such profession.

Behavioral scientists have pointed out that a small degree of psychopathy's attributes - callousness, impulsivity, lack of empathy and superficial charm exists in many of us. Our recent study indicates that a dash of these attributes can actually be healthy for women who want to start businesses.

We surveyed business school students to determine their psychopathic attributes and "entrepreneurial intentions," or predisposition to starting a business. The research found that female students who rated themselves higher in psychopathic attributes also rated higher in entrepreneurial intentions.

Why this effect on women? We believe that it's because stubborn social expectations continue to reward women who are "communal" (nurturing and focused on others), and reward men who are "agentic," or capable of making things happen. This creates an environment in which a modicum of the attributes of psychopathy might help women overcome the typecasting, disregard these norms and do what is necessary.

Our findings show the drawbacks of letting societal rules influence what you want to do with your life. It also shows that entrepreneurial activity doesn't have to be associated with one gender or another, and people shouldn't assume that men are the natural choice for starting a business.

\section{Background}

Psychopathy is usually seen as a negative term, and those who are associated with the term are perceived as dysfunctional. However, psychopathy is similar to any other trait such as empathy, and each of us is likely to fall somewhere on the psychopathy scale. Those with extremely high levels are usually dysfunctional and will be found in institutionalized populations, such as prisons or hospitals. However, many people with lower levels move freely among us. Behavioral scientists say that from five to 15 percent of the non-institutionalized population have some "subcognitive" psychopathic traits, such as limited empathy or wanting to get ahead rather than get along.

Our study drew on role congruity theory (Eagly \& Karau, 2002) to investigate whether some attributes associated with psychopathy moderate the relationship between gender and entrepreneurial intentions. Role congruity pertains to the congruity between gender and other roles, including entrepreneurship (Eagly \& Karau, 2002). Characteristics typical of entrepreneurs are usually defined in agentic terms, which are ascribed more strongly to men. In addition, men, more than women, are concentrated in roles that emphasize power, competition or authority (Eagly, 1987). At the same time, women traditionally have easily entered communal roles that are considered suitable to feminine stereotypes -such as nursing and other professions that involve caring or giving support -- or that put emphasis on human interactions (Eagly, 1987). Hence, the characteristics associated with entrepreneurship roles have traditionally been associated more with men than with women. As a consequence, it is commonly viewed that entrepreneurship is more congruent with the masculine gender role than with the feminine gender role (Eagly \& Karau, 2002).

While society often places great pressure on individuals to adhere to prescribed gender roles, personality characteristics can influence how much he or she chooses to conform. One such personality characteristic is psychopathy. Psychopathy is generally considered an 
undesirable trait in that it manifests as anti-social, callous and impulsive tendencies and a desire to get ahead rather than get along (Babiak \& Hare, 2006). Psychopathy manifests in both clinical and subclinical forms. Clinical psychopathy is characterized by more intense behavior (e.g., rape) as opposed to the less intense subclinical psychopathy (e.g., sexual harassment). Research finds that subclinical psychopaths are able to function in society, while clinical psychopaths are likely incarcerated or institutionalized (Babiak \& Hare, 2006).

We gauged subclinical psychopathy, not clinical, in our research on entrepreneurial intentions. While many of the traits associated with psychopathy are viewed as negative, researchers have suggested that there might be a bright side to psychopathy (Chiaburu, Muñoz, \& Gardner, 2013; Hall \& Benning, 2006), even going so far as to suggest that there is the successful psychopath (Stevens, Deuling, \& Armenakis, 2012; Smith, Watts, \& Lilienfeld, 2012). Indeed, some of the earliest studies in psychopathy suggested that there might be positives associated with psychopathy, especially in business (McCleckley, 1941) and entrepreneurship (Person, 1986). Further, extant research finds that psychopathy has a positive relationship with entrepreneurial intentions (Akhtar, Ahmetoglu, \& Chamorro-Premuzik, 2013). We build on this literature by applying role congruity theory to investigate how psychopathy influences the gender and entrepreneurial intentions relationship. Specifically, we hypothesize that women with higher levels of psychopathy, who have not started a business, are more likely to have intentions to start a venture than women with lower levels of psychopathy.

A touch of psychopathy is not always a bad thing. Such tendencies can actually help both male and female entrepreneurs and others do tough but necessary work that would horrify most of us. An example is Navy SEAL Chris Kyle, depicted in the film "American Sniper," who was cool-headed enough to target even women and children who jeopardized American lives in Iraq. He was able to do things that other people would struggle to do. That takes a certain level of coldness. In business, someone like that might have to go into a tumultuous situation and lay off people to save even more jobs. Many of us are too softhearted to be able to do that, but there are others such as "Chainsaw Al" Dunlap who have little trouble with such activities.

Psychopathic attributes can also make entrepreneurs more determined, for better or worse. A lot of entrepreneurs persist even when others say they should stop. They relentlessly and ruthlessly stay with their ideas. Of course, the downside is that they can miss clues that it's a bad idea. But research shows that sometimes being bold and persistent can help more than it hurts.

\section{Methodology}

We collected data from 209 students from a U.S. business school and had a usable response rate of 160 respondents. The average age of the sample is 21 years with 1 year of work experience. Females represented $44 \%$ of the sample (70/ 160). Using measures of psychopathy (Levenson, Kiehl, \& Fitzpatrick, 1995) and entrepreneurial intentions (Thompson, 2009), while controlling for a range of individual level attributes including age, race, work experience, general selfefficacy (Chen, Gully, \& Eden, 2001), entrepreneurial self-efficacy (McGee, Peterson, Mueller, \& Sequeira, 2009), and the extent to which the individual reported they exhibited traits consistent with ADHD (Kessler, Adler, Ames, Demler, Faraone, et al., 2005).

The students took a standard psychological test that gauges psychopathic attributes in non-institutionalized people. It asked whether they agreed or disagreed with a total of 19 statements, such as "people who are stupid enough to get ripped off usually deserve it," and "before I do anything, I carefully consider the possible consequences." The students another set of questions that measured their likelihood of starting a business. We analyzed the data using hierarchical linear regression analyses in SPSS 23 with the dependent variable of entrepreneurial intentions.

\section{Results \& Conclusions}

Our analysis provides support for our hypotheses that gender has a negative relationship with entrepreneurial intentions, and that psychopathy moderates the gender and entrepreneurial intentions relationship. Specifically, women with higher levels of subclinical psychopathic characteristics, who have not started a business, are more likely to have entrepreneurial intentions than women with lower levels of subclinical psychopathic characteristics.

The research also found that men in general had higher El. But among women, those who ranked themselves the highest in psychopathic attributes had dramatically higher El. Strangely, El dropped among the men who 
ranked themselves higher on the psychopathy scale.

Our findings suggest that men who exhibit some psychopathic attributes and are entrepreneurial would most likely be viewed as having characteristics congruent with an entrepreneur, while women are viewed as not being as congruent with the entrepreneurial role. Psychopathic attributes, considered pejorative for both women and men, is likely a positive in the context of entrepreneurial intentions. Entrepreneurship is potential career choice for women who shatter stereotypes and unwelcome societal role prescriptions. However, the traditional lens for the entrepreneurial profession likely influences a selective bias concerning entrepreneurship. Entrepreneurial characteristics often considered positive in men, but negative in women, may influence women's ability to secure critical support and resources from the entrepreneurial ecosystem in which they operate.

Psychopathy serves as a boundary condition for gender role congruity in the entrepreneurial setting. Both men and women seem to have variance in their El in ways contrary to their gender roles as psychopathy increases. El increased substantially for women as psychopathy increased, and it decreased slightly for men. This shows that psycopathy allows both men and women to eschew traditional gender roles and this, in reality, is why the study is interesting.

Our study has interesting implications for entrepreneurship. First, some subclinical psychopathic attributes appear to have a positive impact on women's ability to reject traditional gender roles and to pursue entrepreneurial endeavors. While most of the current literature portrays traits such as those in the dark triad as dysfunctional, our research suggests that there are some boundary conditions in which they can have a positive impact. While entrepreneurship is generally viewed by society as a masculine profession, our findings suggest that women with characteristics congruent with entrepreneurial characteristics are also attracted to entrepreneurship.

While women are just as capable as men, if not more, at successfully starting new ventures, this study suggests that societal prescriptions likely play a large role in who develops entrepreneurial intentions. The implications of this finding is that as a society we may need to work on eliminating gender biases in our images and definitions of entrepreneurs, but until that happens it has implications for how we train women entrepreneurs.

Of course, it's unclear whether psychopathic attributes help make entrepreneurs' ventures more successful. That's a topic for another study, which we already have underway in a non-student population.

\section{The Takeaway}

- Don't assume that men are more natural entrepreneurs. Societal expectations hold women back from starting business, but it doesn't mean they are less capable.

- Financial backers of companies, and others who support entrepreneurs, need to be genderblind. "Stereotypes of women and entrepreneurship likely not only influence who enters entrepreneurship, but also who receives funding and how much," the report notes.

- Recognize when societal norms are holding you back. A small dose of psychopathic attributes makes it easier to care less about what others think. It might pay to focus on getting ahead rather than getting along sometimes.

- Know yourself. Many people have a harmless, or even productive, level of psychopathic attributes. You have to remember what they are and use them to your advantage. If you think you may have psychopathic tendencies that are too strong, surround yourself with empathetic people you trust who can provide perspective and realistic feedback.

\section{References}

Chen, G., Gully, S.M., \& Eden, D. (2001). Validation of a new general self-efficacy scale. Organizational Research Methods, 4(1), 62-83.

Eagly, A.H., \& Karau, S.J. (2002). Role congruity theory of prejudice toward female leaders. Psychological Review, 109(3), 573-598.

Kessler, R.C., Adler, L., Ames, M., Demler, O., Faraone, S., et al. (2005). The World Health Organization Adult ADHD Self-Report Scale (ASRS): A short screening 
scale for use in the general population. Psychological Medicine, 35(02), 245-256.

Levenson, M.R., Kiehl, K.A., \& Fitzpatrick, C.M. (1995). Assessing psychopathic attributes in a noninstitutionalized population. Journal of Personality and Social Psychology, 68(1), 151-158.

McGee, J.E., Peterson, M., Mueller, S.L., \& Sequeira, J.M. (2009). Entrepreneurial self-efficacy: Refining the measure. Entrepreneurship Theory and Practice, 33(4), 965-988.

Thompson, E.R. (2009). Individual entrepreneur intent: Construct clarification and development of an intentionally reliable metric. Entrepreneurship Theory and Practice, 33(3), 669-694.

\section{Read More:}

Advice, Best Practices and Inspiration for Women Entrepreneurs(https://eiexchange.com/women)

Additional search terms: women, feminism, female founders, women business owners, ambitious women, successful women in business, women in business, psychology, opportunity, research on women, mental illness 